\title{
Hygric Properties of Hemp Bio-Insulations with Differing Compositions
}

Eshrar Latif ${ }^{a^{*}}$, Simon Tucker ${ }^{b}$, Mihaela Anca Ciupala ${ }^{a}$, Devapriya Chitral Wijeyesekera $^{c}$, Darryl Newport ${ }^{\text {a }}$

a School of Architecture, Computing and Engineering, University of East London, University Way, London, E16 2RD, UK.

${ }^{\mathrm{b}}$ Graduate School of the Environment, Centre for Alternative Technology, Machynlleth, Wales, SY20 9AZ, UK.

${ }^{\mathrm{c}}$ Faculty of Civil and Environmental Engineering, Universiti Tun Hussein Onn Malaysia, 86400 Parit Raja, Johor, Malaysia.

\section{Abstract}

The paper presents the results of a laboratory investigation on the hygric properties of five hemp insulation materials commercially available in the UK. The hemp fibre content varies between $30-95 \%$ in the total fibre content of the insulation materials examined. The adsorption-desorption isotherm, moisture buffer value, vapour diffusion resistance factor and water absorption coefficient were determined for the insulation materials investigated. The results showed that the hygric properties of the hemp insulation materials could vary widely depending on the constituents and fibrous structure. The considerable differences noted in the hygric properties of the insulation materials examined could potentially influence their hygrothermal performance as part of a building thermal envelope.

Keywords: Hemp thermal insulation; Hygric properties; Hygrothermal properties; Thermal insulation materials; Moisture buffering; Adsorption isotherm.

\section{Introduction}

Use of sustainable materials is becoming an integral part of the construction process in response to the concerns over resource depletion and global warming. As such, 
sustainability and efficiency are becoming key criteria for selecting thermal insulation materials [1]. Hemp insulation is a plant-based, renewable and carbon-negative thermal insulation material. Among the bio-based thermal insulation materials, hemp insulation is of particular importance in the UK. Hemp is a high yield and low input crop with the additional advantages of being a break crop in cereal rotations. Other benefits include weed control and less field operation. Compared to the conventional mineral and petrochemical based thermal insulation materials like stone wool, glass fibre and expanded polystyrene (EPS) insulations, hemp insulation is a relatively new product. Hence, limited information is available on the hygric and thermal properties of hemp insulations. The effects of hygric properties of insulation materials on the hygrothermal performance of building envelopes are manifold. Moisture can effect heat flux, heat capacity, condensation, mould growth and structural integrity [2]. If the key hygric and thermal properties of the insulations are known, the data can then be assessed individually or can be used in numerical simulation software to study the hygrothermal performance of the materials in building envelope for given hygrothermal boundary conditions. Thus, for example, it can be determined whether a vapour barrier is required in a thermal envelope or how long it will take for a wet insulation to dry out.

This paper characterises five types of hemp insulation materials available in the UK market in terms of the following key hygric properties: adsorption-desorption isotherm, moisture buffer value (MBV), vapour diffusion resistance factor ( $\mu$ value) and water absorption coefficient ( $A$ value). The moisture buffer value represents the materials' relative humidity management capacity in adjacent spaces. The other three parameters (adsorption-desorption isotherm, vapour diffusion resistance factor and water absorption coefficient) can be used in hygrothermal and biohygrothermal 
simulation software to study the hygrothermal performance and mould growth potential of the insulation materials in various building envelopes and climatic conditions.

\section{Theory}

\subsection{Adsorption-desorption isotherm}

Adsorption is the increase in the concentration of a dissolved substance at the interface of a condensed and a liquid or a gaseous phase due to the operation of surface forces [3] . An adsorption isotherm is the constant temperature relationship between the amounts of adsorbate accumulated by the unit quantity of adsorbent in equilibrium condition in a range of partial pressure [4]. An adsorption isotherm can be divided into three distinct regions in relation to water storage functions (Fig. 1).

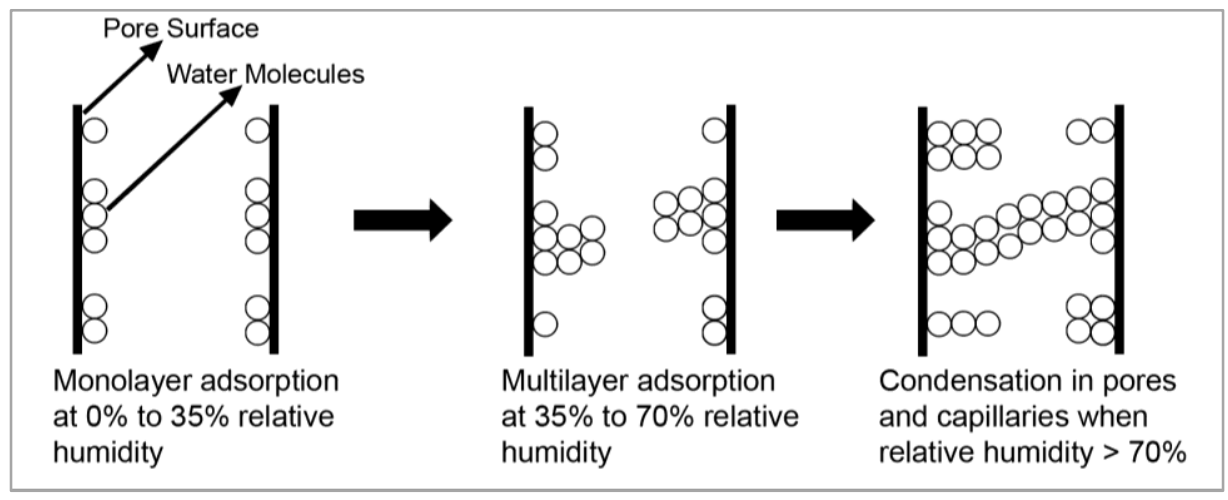

Fig.1. Physisorption, adopted from Osborne [5] .

At lower relative humidity, $0-15 \%$ according to Hill, Norton and Newman [6] and 5$35 \%$ according to Collet et al [7], water molecules are adsorbed in a monolayer (solid solution) on to the internal surfaces of the cell wall. Multi-molecular layers of water are formed on the cell wall micro-capillaries at a relative humidity varying between $15 \%$ and $70 \%$, while capillary condensation occurs at further higher relative humidity ranges. Area covered by $0 \%$ to $95-98 \%$ relative humidity is defined as hygroscopic region. Adsorption isotherms, in subcritical temperature, are classified by the 
International Union of Pure and Applied Chemistry (IUPAC) into six distinct types [8], as shown in Fig. 2.

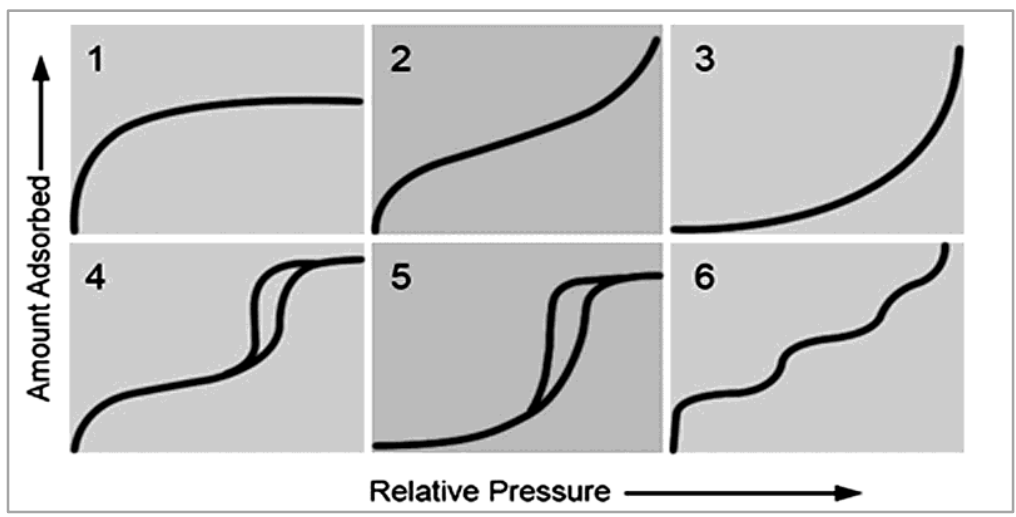

Fig. 2. IUPAC classification of adsorption isotherms.

Type 1 corresponds to Langmuir isotherm describing monolayer adsorption on microporous (pore widths below $2 \mathrm{~nm}$ ) adsorbent. Type 2 describes adsorption on macroporous adsorbent with adsorbent-adsorbate interaction. There is initial formation of monolayer and subsequent formation of multilayer. Type 3 describes multilayer isotherm on macroporous absorbent with week adsorbent-adsorbate interaction. Type 4 and 5 represent adsorption isotherm with hysteresis. Capillary condensation occurs in mesopores (pore widths from 2 to $50 \mathrm{~nm}$ ) in these two types. Type 6 includes steps that occur due to phase transition of adsorbed molecular layer or due to adsorption on different faces of crystalline solids.

\subsection{Moisture buffering}

Moisture buffer capacity is a property by which hygroscopic materials in touch with surrounding air adsorb and desorb moisture to create equilibrium with the relative humidity of the surrounding space. Moisture buffering capacity can be used for moderating the humidity fluctuations in internal spaces. Several quantitative methods are available to determine and represent moisture buffering capacity such as the method developed by the Organisation for Testing in the Nordic Countries (NORDTEST) [9] , Japanese Standards [10], ISO standard [11] and the method 
proposed by Padfield [12]. Among them, NORDTEST method is mostly used in the European context. The three ways of representing moisture buffering capacity described by NORDTEST method are explained in subsections 2.2.1- 2.2.3.

\subsubsection{Moisture effusivity}

Moisture effusivity $\left(b_{m}\right)$ is the measure of the ability of the material to exchange moisture with its surroundings when the surface of the material is exposed to sudden change in humidity. The equation for moisture effusivity is:

$b_{m}=\sqrt{\frac{\delta_{p} \cdot \rho_{0} \cdot\left(\frac{\partial u}{\partial \varphi}\right)}{P_{s}}}$

Where $b_{m}$ is the moisture effusivity $\left[\mathrm{kg} /\left(\mathrm{m}^{2} \cdot \mathrm{Pa} \cdot \mathrm{s}^{1 / 2}\right)\right], \delta_{p}$ is the vapour permeability $[\mathrm{kg} /(\mathrm{m} . \mathrm{s} . \mathrm{Pa})], \rho_{o}$ is the dry density of the material $\left(\mathrm{Kg} / \mathrm{m}^{3}\right), u$ is the moisture content $(\mathrm{kg} / \mathrm{kg}), \varphi$ is the relative humidity $(-), P_{s}$ is the saturation vapour pressure $(\mathrm{Pa})$.

\subsubsection{Ideal moisture buffer value}

The most common step change function for moisture buffering is to expose the surface to $75 \%$ relative humidity for 8 hours and to $33 \%$ relative humidity for 16 hours in each testing cycle. The equation for the relationship between surface moisture flux and time is:

$G(t)=\int_{0}^{t} g(t) d t=b_{m} \cdot \Delta P \cdot h(\alpha) \cdot \sqrt{\frac{t_{p}}{\pi}}$

Where $G(t)$ is the accumulated moisture uptake $\left(\mathrm{kg} / \mathrm{m}^{2}\right)$ and the corresponding moisture release during a time period $t_{p}, g(t)$ is the moisture flux over the surface at time $t$ and $h(\alpha)$ can be expressed by the following equation:

$h(\alpha)=\frac{2}{\pi} \sum_{n=1}^{\infty} \frac{\operatorname{Sin}^{2}(n \pi \alpha)}{n^{3 / 2}} \approx 2.252[\alpha(1-\alpha)]^{0.535}$ 
where $\alpha$ is the fraction of the time period when moisture load is high. In this case the value of $\alpha=1 / 3$ and $h(\alpha)=1.007$ and therefore Eq. 2 becomes:

$G(t) \approx 0.568 \cdot b_{m} \cdot P_{s} \cdot \sqrt{t_{p}}$

The value $\left(M B V_{\text {ideal }}\right)$ is determined by dividing Eq. 4 by the change in relative humidity, as follows:

$M B V_{\text {ideal }} \approx \frac{G(t)}{\Delta R H}=0.568 \cdot b_{m} \cdot P_{s} \cdot \sqrt{t_{p}}$

Where $\triangle R H$ is the change of relative humidity (\%). $M B V_{\text {ideal }}$ is measured in $\left[\mathrm{kg} /\left(\mathrm{m}^{2} . \% \mathrm{RH}\right)\right]$

\subsubsection{Practical moisture buffer value}

Practical moisture buffer value $M B V_{\text {practical }}$ is the amount of moisture content that passes through the unit open surface of the material during a certain period of time when the material is exposed to variation in relative humidity of the surrounding air. The unit of $M B V_{\text {practical }}$ is $\left[\mathrm{kg} /\left(\mathrm{m}^{2} . \% \mathrm{RH}\right)\right]$.

\subsection{Vapour permeability and vapour diffusion resistance factor}

Moisture transfer occurs through porous materials when there is vapour pressure differential between two opposite surfaces. Fick's law [13] expresses isothermal moisture transfer by the following equation:

$\mathrm{g}_{\mathrm{v}}=-\delta \cdot \nabla \rho_{v}$

Where $g_{v}$ is the vapour/moisture flux $\left[\mathrm{kg} /\left(\mathrm{m}^{2} . \mathrm{s}\right)\right], \delta$ is the vapour permeability of the porous system in the material $[\mathrm{kg} /(\mathrm{m} . \mathrm{s} . \mathrm{Pa})], \rho_{v}$ is the water vapour partial pressure $(\mathrm{Pa})$.

Vapour diffusion resistance factor is introduced by Krischer [13] on the basis that vapour flow rate through a unit surface of air is always higher than that through a unit 
surface of a porous material. The equation for the vapour diffusion resistance factor is expressed as:

$$
\mu=\frac{\delta_{a}}{\delta}
$$

Where $\mu$ is the vapour diffusion resistance factor $(-), \delta_{a}$ is the vapour permeability of air $[\mathrm{kg} /(\mathrm{m} . \mathrm{s} . \mathrm{Pa})]$.

The diffusion equation is expressed in terms of vapour diffusion resistance factor as follows:

$g_{v}=\frac{\delta_{a} \cdot \nabla \rho_{v}}{\mu}$

Vapour transmission property is also expressed in terms of the thickness of a motionless air layer which has the same water vapour resistance as the test specimen and expressed as the water vapour diffusion equivalent air-layer thickness ( $S_{d}$ value). $S_{d}$ is expressed in meters $(\mathrm{m})$ and is given by the following equation:

$S_{d}=\mu . d$

Where $d$ is the thickness of the sample $(\mathrm{m})$.

\subsection{Water absorption coefficient}

When a porous material is in direct contact with liquid water, water will be absorbed by the free water surface into the material by capillary forces. When the contact is removed, water can be redistributed in the material. The amount of water absorbed is proportionate to the square root of time. The water absorption coefficient or ' $A$ ' value is thus expressed as the ratio of water flux through the free water surface and the square root of time and is determined by a one-directional free water intake test. Materials with higher water absorption coefficient can effectively manage liquid water in situations such as direct exposure to driving rain, surface diffusion, etc. Materials 
are more susceptible to the exposure to water during the construction phase than in service conditions.

\section{Material and method}

\subsection{Material}

Five commercially available hemp insulation materials in the UK are selected for hygric characterisation. Their commercial names are replaced by the following names: Hemp-1, Hemp-2, Hemp-3, Hemp-4 and Hemp-5. The properties of the insulation materials investigated are summerised in Table1.

Table 1. Summary of the insulation properties.

\begin{tabular}{|c|c|c|c|c|c|}
\hline Materials & $\begin{array}{l}\text { Measured } \\
\text { mean } \\
\text { density } \\
\left(\mathrm{Kg} / \mathrm{m}^{3}\right)\end{array}$ & $\begin{array}{l}\text { Measured } \\
\text { mean } \\
\text { thickness } \\
(\mathrm{mm})\end{array}$ & Constituents & $\begin{array}{l}\text { Declared } \\
\text { specific heat } \\
\text { capacity } \\
(\mathrm{J} / \mathrm{kg} . \mathrm{K})\end{array}$ & $\begin{array}{l}\text { Declared dry } \\
\text { thermal } \\
\text { conductivity } \\
(\mathrm{W} / \mathrm{m} . \mathrm{K})\end{array}$ \\
\hline Hemp-1 & 55 & 48 & $\begin{array}{l}30 \% \text { hemp fibre, } 60 \% \text { wood } \\
\text { fibre, } 10 \% \text { polyester. }\end{array}$ & 1700 & 0.038 \\
\hline Hemp-2 & 50 & 55 & $\begin{array}{l}85 \% \text { hemp fibres, } 10-12 \% \\
\text { bi-component fibres and } \\
3-5 \% \text { soda. }\end{array}$ & 1600 & 0.038 \\
\hline Hemp-3 & 60 & 47 & $\begin{array}{l}70 \% \text { hemp fibres, } 15 \% \\
\text { hemp shive, } 8 \% \text { mmonium } \\
\text { phosphate, } 7 \% \text { polyolefin } \\
\text { fibres }\end{array}$ & 1700 & 0.043 \\
\hline Hemp-4 & 39 & 45 & $\begin{array}{l}95 \% \text { hemp fibres and } \\
5 \% \text { combination recycled } \\
\text { adhesive binder. }\end{array}$ & 1700 & 0.039 \\
\hline Hemp-5 & 45 & 57 & $\begin{array}{l}35 \% \text { hemp fibre, } 35 \% \\
\text { recovered waste cotton } \\
\text { fibre, } 15 \% \text { bi-component } \\
\text { polyester fibre and } 15 \% \text { fire } \\
\text { retardant. }\end{array}$ & 1700 & 0.039 \\
\hline
\end{tabular}

Figure 3 shows the scanning electron microscopy (SEM) images of the hemp insulations. The average diameter of hemp hemp fibre bundles in hemp insulations are as follows: $43 \mu \mathrm{m}$ for Hemp-1, $46 \mu \mathrm{m}$ for Hemp-2, $24 \mu \mathrm{m}$ for Hemp-3, $55 \mu \mathrm{m}$ for Hemp-4, $40 \mu \mathrm{m}$ for Hemp-5. Fast Fourier Transform (FFT) of the images shows that fibres are randomly oriented in all insulation materials analysed. 


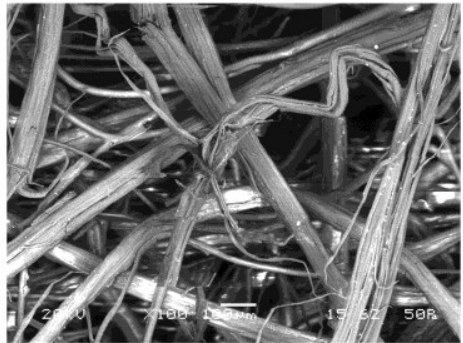

(a)

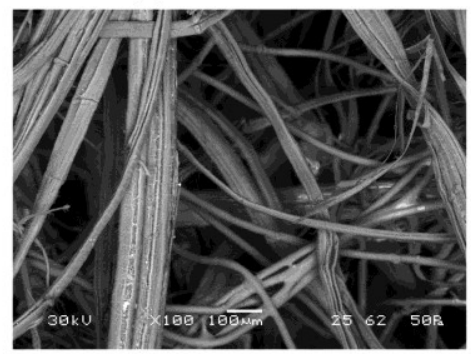

(d)

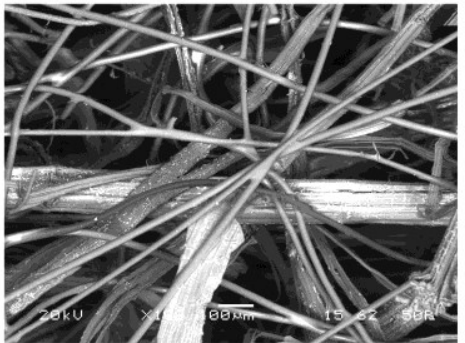

(b)

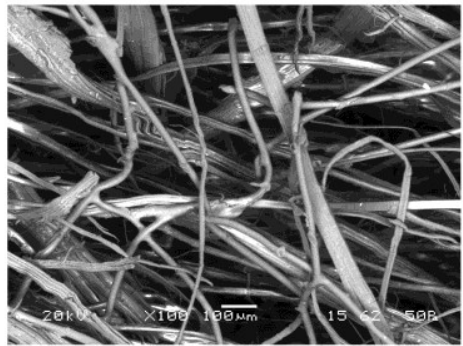

(e)

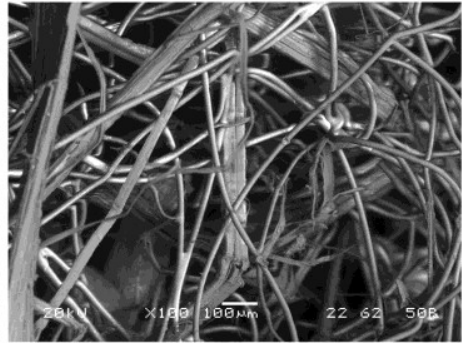

(c)

Fig. 3. SEM images of the hemp insulations at 100X magnification: (a) Hemp-1, (b) Hemp-2, (c) Hemp-3, (d) Hemp-4, (e) Hemp-5.

\subsection{Method}

\subsubsection{Determination of adsorption-desorption isotherms}

\subsubsection{Method}

The methods for experimentally determining the adsorption-desorption isotherms of thermal insulating materials are outlined in the British Standard BS EN ISO 12571 [14]. Three samples of a dimension of $200 \mathrm{~mm} \mathrm{X} 200 \mathrm{~mm}$ with true thickness are initially dried in a ventilated oven at $40 \pm 2{ }^{\circ} \mathrm{C}$ and less than $10 \%$ relative humidity to reach constant mass. Constant mass is considered to be reached when the change in the mass of the test specimens over a 24 hour period is less than $0.1 \%$ of the total mass when weighed in a scale with an uncertainty not greater than $0.1 \%$. The precision scale that was used had both readability and repatability of 0.001 grams (g). To determine the adsorption isotherm, the samples are consecutively exposed to minimum four evenly distributed increasing humidity conditions between $30 \%$ to $95 \%$ while keeping the temperature constant at $23( \pm 0.5){ }^{\circ} \mathrm{C}$ in a climate chamber. For 
determining the desorption isotherm, the process is carried out in reverse order. During each exposure, the samples have to reach equilibrium moisture content $(E M C)$. For EMC, constant mass is reached if the change of mass between three consecutive weighings, each made at least 24 hours apart, is less than $0.1 \%$ of the total mass. To study the kinetics of adsorption, the mass of the samples were measured at every 8 hours during the adsorption phase.

The adsorption/desorption of moisture content by weight $U(\mathrm{~kg} / \mathrm{kg})$ is calculated as follows:

$U=\frac{m-m_{0}}{m_{0}}$

Where, $m_{0}$ is the mass of the material at dry condition $(\mathrm{kg})$ and $m$ is the mass of the material at the equilibrium moisture content at any relative humidity $(\mathrm{kg})$.

\subsubsection{Analysis of adsorption-desorption Isotherm}

The 'Guggenheim, Andersen and de Boer' (GAB) equation [15] has been selected for the interpretation of the experimental adsorption data. The GAB isotherm is based on further modification of Brunauer, Emmett and Teller (BET) isotherm [15]. Like the BET formulation, the GAB formulation also assumes that adsorbate molecules beyond the first layer are similar. However, according to the GAB model, the states of the other adsorbate layers are different at pure liquid state. For this reason, the $\mathrm{GAB}$ equation introduces an additional parameter, namely $K$, that determines the state of the adsorbed molecules beyond the first layer [15]. The equation for the GAB isotherm is:

$W(\varphi)=\frac{W_{m G} \mathrm{C}_{\mathrm{G}} \mathrm{K} \varphi}{(1-K \varphi)\left[1+\left(\mathrm{C}_{\mathrm{G}}-1\right) \mathrm{K} \varphi\right]}$

Where $W$ is the moisture content of the material on a dry basis $(-), C_{G}$ is the energy constant related to the difference of free enthalpy of water molecules in the liquid 
state and in the monolayer and is defined as the ratio of the partition function of the first molecule adsorbed on a site and the partition function of the molecules adsorbed beyond the first molecule in the multilayer. $W_{m G}$ is the temperaturedependent monolayer value in the same unit as $W$ and it is the measure of the availability of active site for water sorption. $\mathrm{K}$ is a constant, characterizing the state of the adsorbed molecules beyond the first layer.

The linearized function of the GAB isotherm is:

$F(\mathrm{GAB}) \equiv \frac{\varphi}{(1-\mathrm{K} \varphi) W(\varphi)}=\frac{1}{\mathrm{C}_{\mathrm{G}} \mathrm{K} W_{m G}}+\frac{\mathrm{C}_{\mathrm{G}}-1}{\mathrm{C}_{\mathrm{G}} W_{m G}} \varphi$

The GAB equation has been chosen for its higher coverage of activity range for monolayer sorption values $(0.05<\varphi<0.8-0.9)[7]$ compared to that of BET equation $(0.05<\varphi<0.3) . K$ value is determined from the best linearization plot of $F(G A B)$ versus $\varphi$. The other two constants, $W_{m G}$ and $\mathrm{C}_{\mathrm{G}}$, are then determined from two linear regression coefficients.

\subsubsection{Determination of moisture buffer value}

The moisture buffering experiment was carried out according to the NORDTEST protocol [9]. Three samples of insulation materials were used in the experiment. Each sample had an exposed surface area of $100 \mathrm{~mm} \times 100 \mathrm{~mm}$. The other five surfaces of each sample were sealed with aluminium foil tape, as shown in Fig. 4.

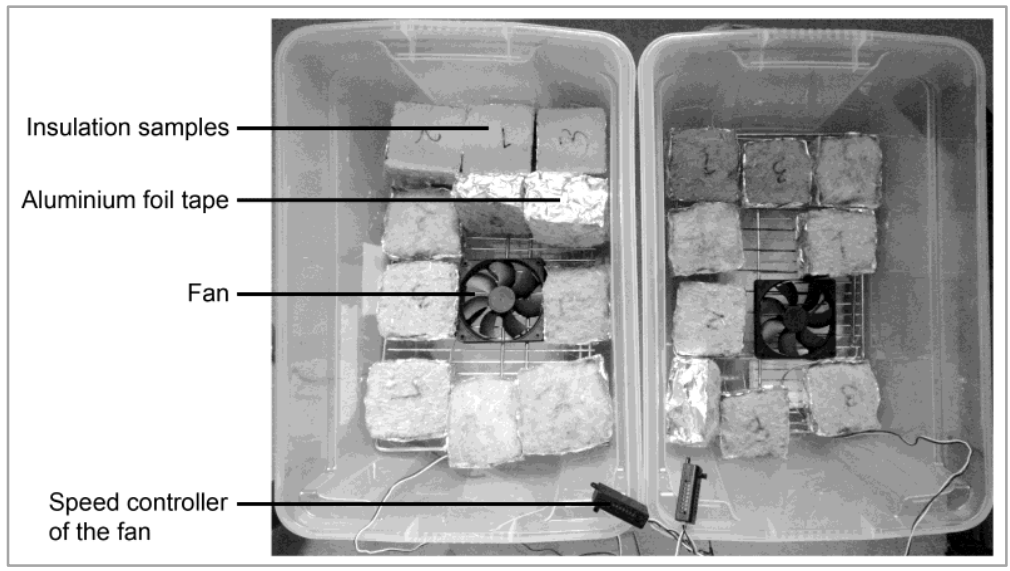

Fig.4. Moisture buffering test setup. 
The thickness of each sample was the actual product thickness. The test conditions are shown in Table 2. The materials are exposed to cyclic relative humidity conditions. Each 24 -hour cycle is a combination of 8 -hour exposure to $75 \%$ relative humidity and 16 -hour exposure to $33 \%$ relative humidity at $23{ }^{\circ} \mathrm{C}$ temperature. As suggested by the NORDTEST method, air velocity of $0.1 \pm 0.05 \mathrm{~m} / \mathrm{s}$ is maintained by two fans with controllers, as shown in Fig. 4.

Table 2. The test conditions of moisture buffering for all the insulation samples.

\begin{tabular}{|c|c|c|c|}
\hline Temperature $\left({ }^{\circ} \mathrm{C}\right)$ & Relative Humidity (\%) & $\begin{array}{l}\text { Exposure } \\
\text { (Hours) }\end{array}$ & Salt Used \\
\hline $23 \pm 0.5$ & $33 \pm 3$ & $16 \pm(10$ minutes $)$ & $\mathrm{MgCl}_{2}$ \\
\hline $23 \pm 0.5$ & $75 \pm 3$ & $8 \pm(10$ minutes $)$ & $\mathrm{NaCl}$ \\
\hline
\end{tabular}

At each of the cycles, the change of mass of the insulation samples $\Delta m(\mathrm{~g})$ is calculated as the average of the mass gain during adsorption and mass loss during desorption. The measurement of mass was performed by a precision scale with readability and repeatability of $0.001 \mathrm{grams}(\mathrm{g})$. The experiment is continued until there is not more than $5 \%$ variation in 3 consecutive determinations of $\Delta m$. Kinetics of mass was measured during the final cycle. $M B V_{\text {practical }}$ is expressed as weight change per $\mathrm{m}^{2}$ per $\Delta \mathrm{RH}$ and is measured in $\mathrm{g} /\left(\mathrm{m}^{2} . \% \mathrm{RH}\right)$.

In loft applications, insulations are directly exposed to the ambient conditions of the loft space and in wall applications, insulations are usually covered with a $12.5 \mathrm{~mm}$ layer of plasterboard. Moisture buffer tests were carried out to simulate both situations.

\subsubsection{Determination of vapour diffusion resistance factor}

The vapour diffusion resistance factor of thermal insulating materials can be determinded following the British Standard BS EN 12086 [16]. Five samples of a dimension of $100 \mathrm{~cm}^{2}$ and thickness of $40 \mathrm{~mm}-100 \mathrm{~mm}$ are intially conditioned for at 
least 6 hours at $(23 \pm 2)^{\circ} \mathrm{C}$ temperature and $(50 \pm 5) \%$ relative humidity to reach constant mass. The insulation specimens are placed on glass dishes containing salt solutions or dessicants, depending on the test type (dry cup or wet cup). The sides of the insulations are adequately sealed to achieve one directional moisture flow. For the dry cup test, the relative humidity inside the dishes is $0 \%$ and outside the dishes is $50( \pm 3) \%$. For wet cup test, the relative humidity inside the dishes is $50( \pm 3) \%$ and outside the dishes is $93( \pm 3) \%$. The test assembly is then conditioned in the climate chamber for 1 to 24 hours. The differential of partial vapour pressure between 'in the atmosphere' and 'in the test assembly' drives the vapour through the specimen. The assembly is weighed at every 24 hours until five successive determinations of change in mass per unit time for each specimen in $\pm 5 \%$ of the mean value.

The rate of change in mass is calculated from the following equation:

$$
\mathrm{G}_{1,2}=\frac{\left(m_{2}-m_{1}\right)}{\left(t_{2}-t_{1}\right)}
$$

Where $m_{1}(\mathrm{mg})$ is the mass of the test assembly at time $t_{1}, m_{2}$ is the mass of the test assembly at time $t_{2}$. The times $t_{1}$ and $t_{2}$ are successive times of weighing (hour), $G$ is the mean of five successive determinations of $G_{1,2}(\mathrm{mg} / \mathrm{h})$, and $G_{1,2}$ is within $\pm 5 \%$ of G. The vapour diffusion resistance factor, $\mu$, is calculated using Eq. 7. Vapour permeability $\delta$ is calculated from the following expression:

$\delta=W \cdot d$

Where $W$ is the water vapour permeance $\left[\mathrm{mg} /\left(\mathrm{m}^{2}\right.\right.$.h.Pa $\left.)\right]$ and $d$ is the test specimen thickness $(\mathrm{m}) . W$ is determined from the following expression:

$$
W=\frac{G}{A \cdot \Delta \rho}
$$


Where $A$ is the surface area of the specimen $\left(\mathrm{m}^{2}\right)$ and $\Delta \rho$ is the pressure difference (Pa) as set in BS EN 12086. The vapour diffusion equivalent air-layer thickness $\left(S_{d}\right.$ value) is calculated using Eq. 9.

The aforementioned method of measuring vapour diffusion resistance factor did not take into account the surface vapour resistance of materials. The vapour diffusion resistance factors are, therefore, carried out with this limitation.

\subsubsection{Determination of $A$ value}

The methods for experimentally determining water absorption coefficient ( $A$ value) of the building materials by partial immersion are outlined in the British Standard BS EN 15148 [17]. The test specimens are conditioned to the temperature of $18{ }^{\circ} \mathrm{C}$ to 28 ${ }^{\circ} \mathrm{C}$ with allowed temperature variation during the tests of $\pm 2{ }^{\circ} \mathrm{C}$ and relative humidity of $40 \%$ to $60 \%$ with allowed relative humidity variation during tests of $\pm 5 \%$. The insulation samples are conditioned to the test condition so that the change of mass is $0.1 \%$ of total mass when measured over 24 -hour intervals. Samples are placed in a tank, resting on point supports so that the bases of the samples do not touch the tank surfaces, as shown in Fig. 5.

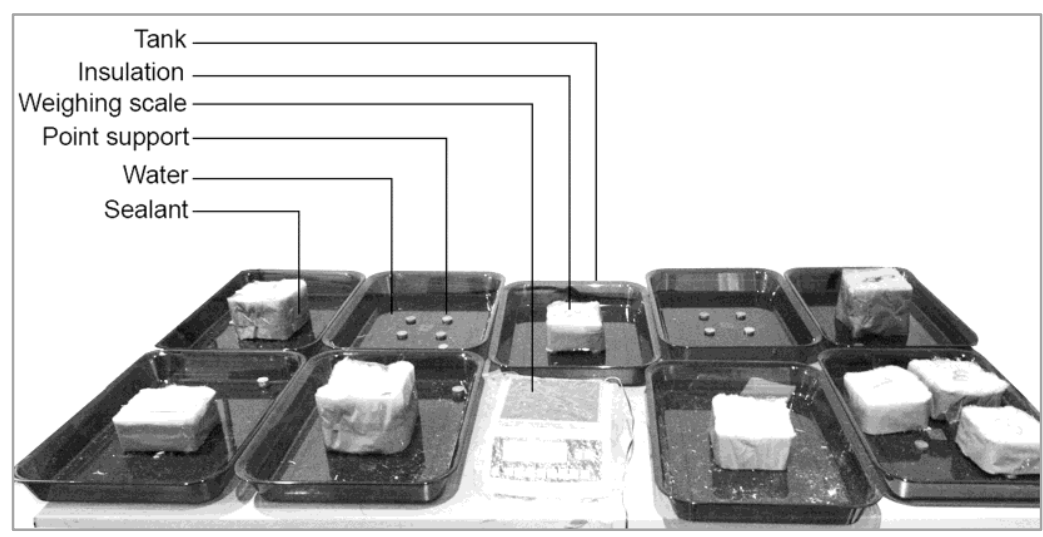

Fig. 5. Setup for assessing water absorption coefficient (A value).

The tanks are filled with water so that the water level is $(5 \pm 2) \mathrm{mm}$ above the highest point of the base of the specimen. The sides of the samples are sealed with water and vapour tight sealant. All samples are weighed at the following times from the 
beginning of the experimental work: 5 minutes, 20 minutes, 1 hour, 2 hours, 4 hours, 8 hours, 16 hours and 24 hours. The difference of mass per area $(W)$ between each weighing and the initial weighing is measured using the following equations:

$W=\frac{m_{t}-m_{i}}{a}$

Where $m_{t}$ is the mass at any time of weighing $(\mathrm{kg}), m_{i}$ is the mass at initial weighing $(\mathrm{kg})$ and $a$ is the surface area of the sample in contact with water $\left(\mathrm{m}^{2}\right)$.

According to the British Standard BS EN 15148, the $A$ value can be expressed as $A_{w}, W_{w}, A_{w, 24}$ or $W_{w, 24}$. To determine the $A$ value, $\Delta m_{t}=m_{t}-m_{i}$ is plotted against the square root of the weighing times. When a straight line can be drawn through the values of $\Delta m_{t}$, the line is extrapolated back to zero time where the value of the intercept is $\Delta m_{0}^{\prime}$. In this case, the water absorption coefficient is denoated by $A_{w}$ or $W_{w}$ and it can be determined by using either Eq. 17 or Eq. 18.

$$
\begin{aligned}
& A_{w}=\frac{\Delta \mathrm{m}^{\prime}{ }_{t f}-\Delta \mathrm{m}^{\prime}{ }_{0}}{\sqrt{t f}} \\
& W_{w}=\frac{\Delta \mathrm{m}^{\prime}{ }_{t f}-\Delta \mathrm{m}^{\prime}{ }_{0}}{\sqrt{t f}}
\end{aligned}
$$

Where $\Delta m_{t f}^{\prime}\left(\mathrm{kg} / \mathrm{m}^{2}\right)$ is the value of $\Delta m$ at 'tf time. The time 'tf is 1 day expressed in seconds in Eq. 17 and 1 day expressed in hours in Eq. 18.

When the plot of $\Delta m_{t}$ against square root of the time does not give a straight line, the water absorption coefficient is denoted by $A_{w, 24}$ or $W_{w, 24}$ and it can be expressed by using either Eq. 19 or Eq. 20.

$$
\begin{aligned}
& A_{w, 24}=\frac{\Delta \mathrm{m}^{\prime}{ }_{t f}}{\sqrt{t f}} \\
& W_{w, 24}=\frac{\Delta \mathrm{m}^{\prime} t f}{\sqrt{t f}}
\end{aligned}
$$


Where $\Delta m_{t f}^{\prime}\left(\mathrm{kg} / \mathrm{m}^{2}\right)$ is the value of $\Delta m$ at 'tf time. The time 'tf is 1 day expressed in seconds in Eq. 19 and 1 day expressed in hours in Eq. 20.

\section{Results and discussion}

\subsection{Adsorption-desorption isotherm}

The adsorption and desorption isotherm of the insulation samples are shown in

Fig. 6 in terms of average percentage mass gain per unit dry mass (AMCw).

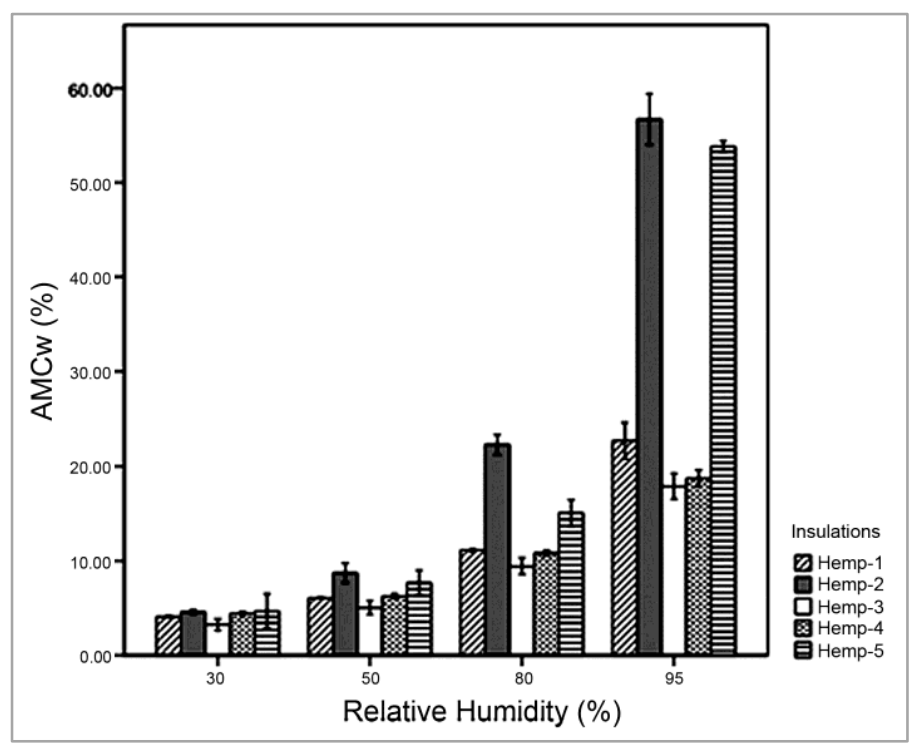

Fig. 6. Average moisture content by percentage mass gain per unit dry mass (AMCw) with 1 standard deviation.

Hemp-2 and Hemp-5 are the most hygroscopic materials while the other insulations are in the middle range in terms of moisture adsorption. This middle range, about $15 \%$ to $25 \%$ moisture gain, can be assumed as the typical range for most of the hemp fibres, as this is the range reported by most of the experimental determinations of adsorption isotherms [7],[18]. The high adsorption capacity of Hemp-2 and Hemp5 can be advantageous in terms of controlling internal relative humidity and minimising interstitial condensation in an environment with cyclic variations of relative humidity. It can also be observed that in both Hemp-2 and Hemp-5 insulations the respective adsorption capacities are rapidly increasing at higher water activity ranges, especially between $80 \%$ to $95 \%$ relative humidity. At higher water 
activity (starting from $70 \%$ relative humidity), transient micro capillary network is developed in the cellulose and lignocellulosic fibres and capillary condensation becomes increasingly dominant [6]. At the same time, more adsorption sites open up due to the swelling of the cells. The observed difference in moisture uptake behaviour of different fibres at higher water activity may be due to the fibrous structure of the insulations, porosity and different methods of processing of the fibres, resulting in different mechanical and sorption properties.

The adsorption-desorption isotherms of selected insulation materials based on the GAB regression together with the experimental data of average moisture content by weight (AMCw) are shown in Figs. 7-11. It can be noticed that the experimental data fits well with the GAB model in most of the cases up to $80 \%$ relative humidity. Hysterisis is observed in Hemp-1, Hemp-2 and Hemp-3. Hysteresis is more pronounced in Hemp-1 and Hemp-3 insulation materials which contained wood and hemp shivs, respectively.

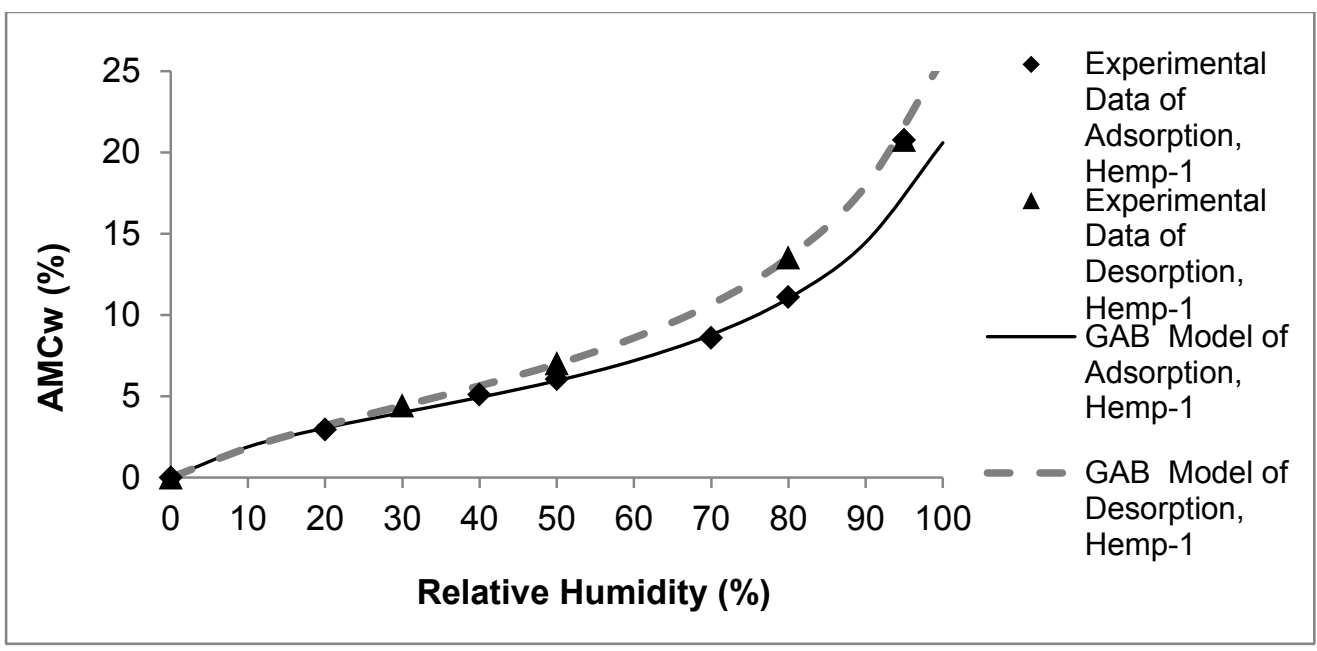

Fig. 7. Adsorption-desorption isotherm (AMCw) of Hemp-1 with GAB fit. 


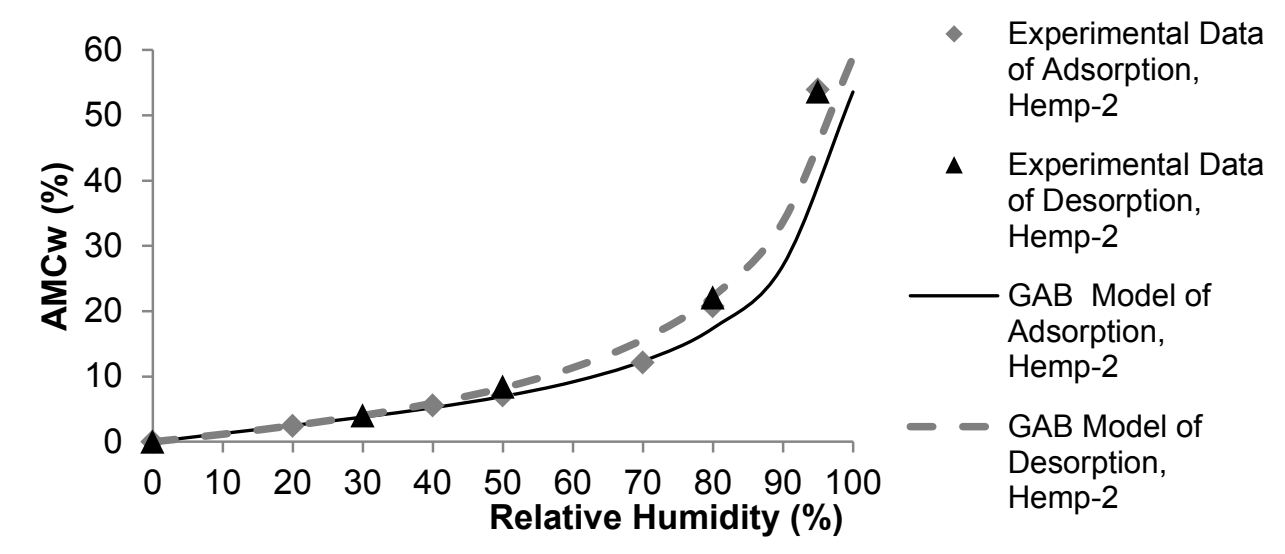

Fig. 8. Adsorption-desorption isotherm (AMCw) of Hemp-2 with GAB fit.

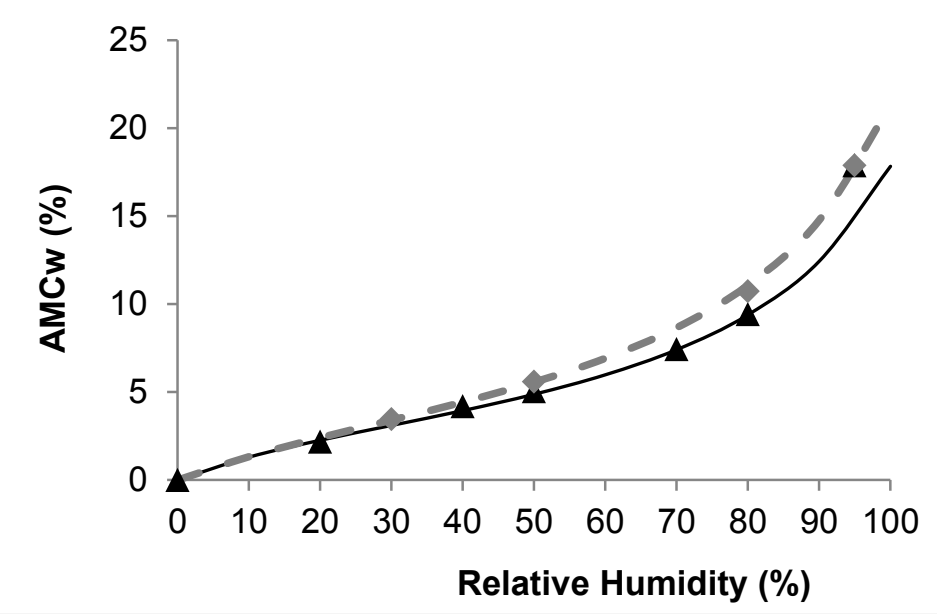

$\Delta \quad$ Experimental Data of Adsorption, Hemp-3

- Experimental Data of Desorption, Hemp-3 GAB Model of Adsorption, Hemp-3

- GAB Model of Desorption, Hemp-3

Fig. 9. Adsorption-desorption isotherm (AMCw) of Hemp-3 with GAB fit.

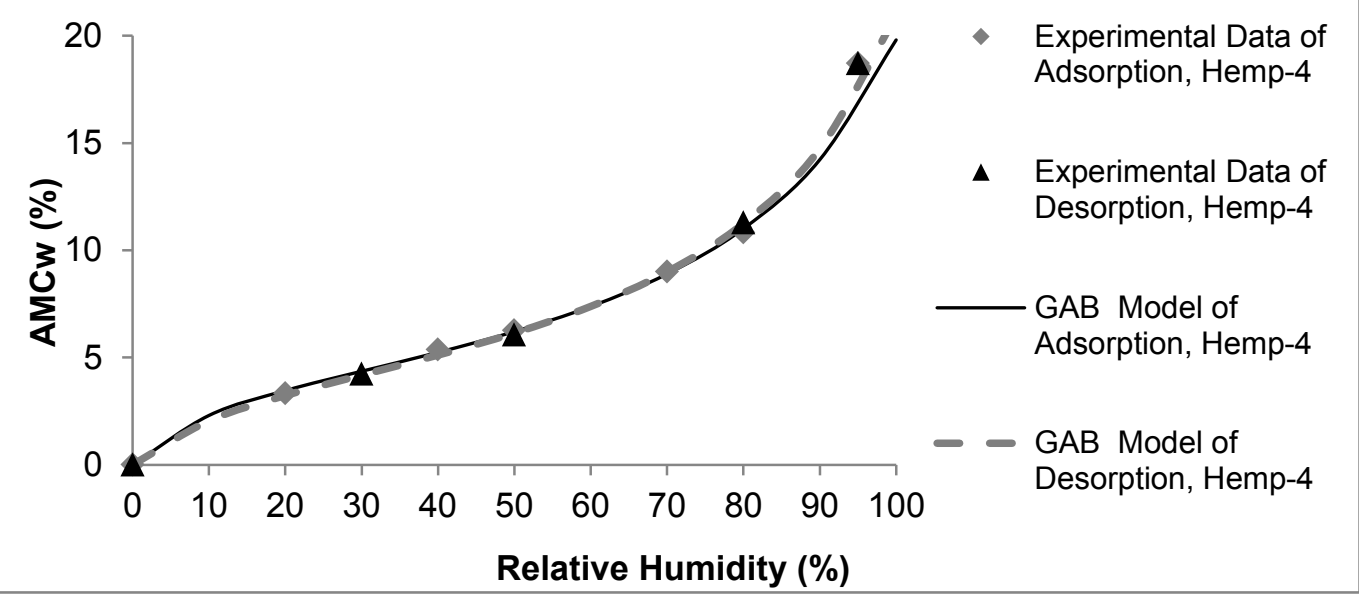

Fig. 10. Adsorption-desorption isotherm (AMCw) of Hemp-4 with GAB fit 


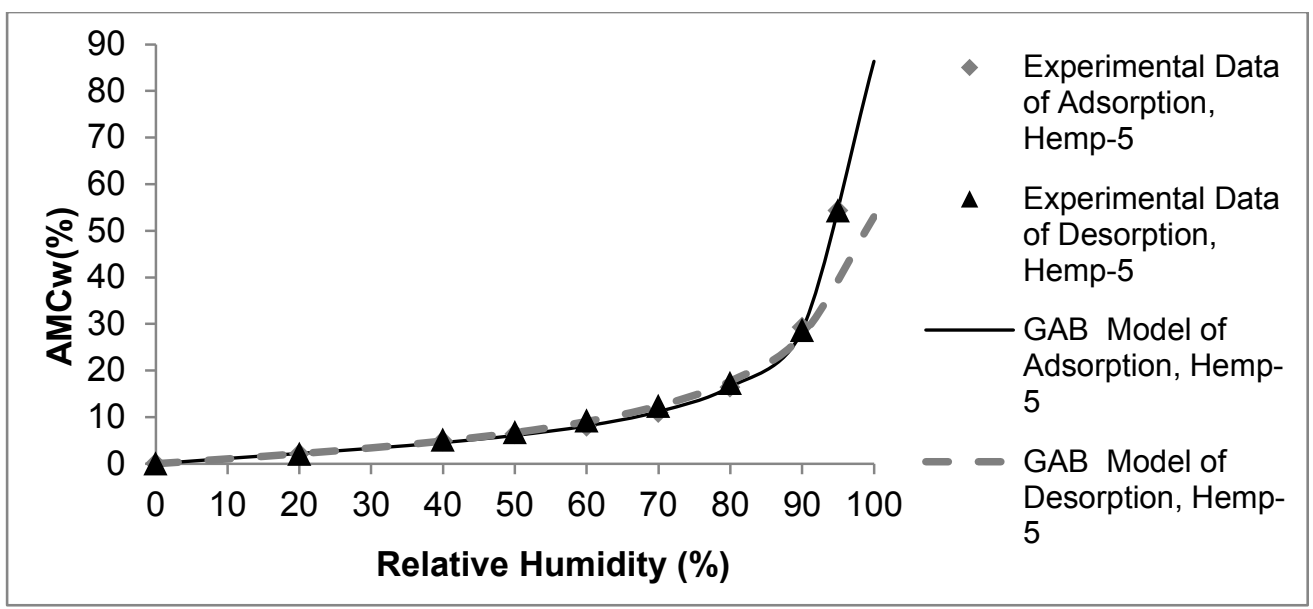

Fig. 11. Adsorption-desorption isotherm (AMCw) of Hemp-5 with GAB fit.

The GAB parameters for adsorption isotherms of the hemp insulations are provided in Table 3 . It can be noted that more active sites for monolayer water sorption, as represented by higher value of $W_{m g}$, are available in Hemp-2 and Hemp-5 insulations. It can also be noted that higher entropy and liquid state, as represented by higher $\mathrm{K}$ value, are also present in Hemp-2 and Hemp-5 insulations.

Table 3. GAB parameters for the insulation materials.

\begin{tabular}{|l|cccc|}
\hline Material & \multicolumn{4}{|c|}{ GAB parameters } \\
\cline { 2 - 5 } & ${\operatorname{Temp~}\left({ }^{\circ} \mathrm{C}\right)}_{\mathrm{C}}$ & $\mathrm{C}_{\mathrm{g}}$ & $\mathrm{K}$ & $\mathrm{W}_{\mathrm{mg}}$ \\
\hline Hemp-1 & 23 & 7.9 & 0.8 & 0.042 \\
Hemp-2 & 23 & 2.65 & 0.9 & 0.056 \\
Hemp-3 & 23 & 5.45 & 0.8 & 0.037 \\
Hemp-4 & 23 & 11.54 & 0.79 & 0.042 \\
Hemp-5 & 23 & 2.91 & 0.95 & 0.044 \\
\hline
\end{tabular}

The GAB models of isotherms of products of biological origin are commonly represented by sigmoidal (IPAC type 2) shapes [6, 18]. However, it can be observed that while the sorption curves of Hemp-2 and Hemp-5 are not truly sigmoidal, they can be expressed in terms of the modified classification (Type Ila) of GAB-like sorption isotherms (Fig. 12), as observed by Blahovec and Yanniotis [19]. Similar sigmoidal and non-sigmoidal regression lines (Type Ila and Type IIb) were also 
presented by Collet et al [7] while comparing two hemp insulations using the BET and GAB models.

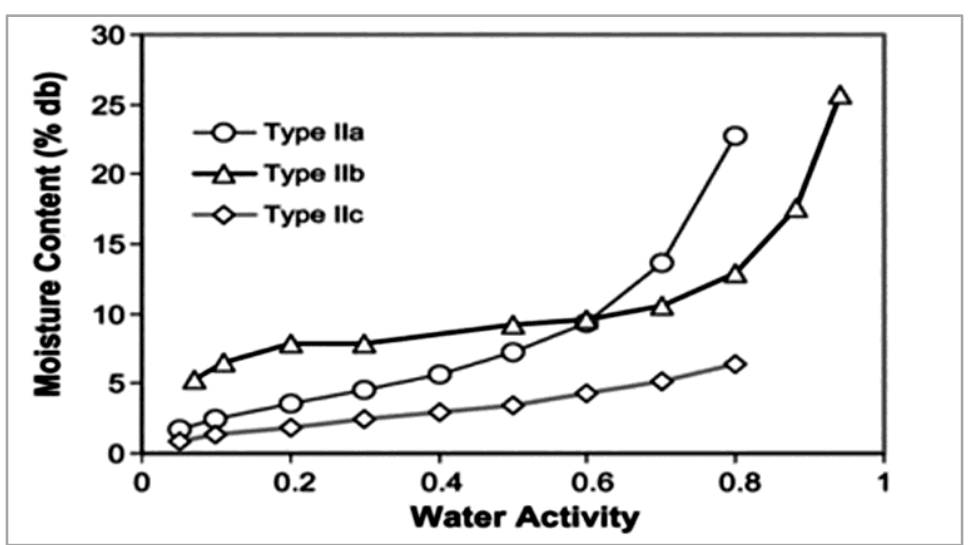

Fig. 12. Modified classification of type II isotherms [20].

Fig. 13 shows the adsorption kinetics of the hemp insulation materials for the period of 44.6 days. It can be noted that moisture content of Hemp-2 and Hemp-5 increases by 2.4 and 3.4 times, respectively, in response to the rise of relative humidity from $80 \%$ to $95 \%$.

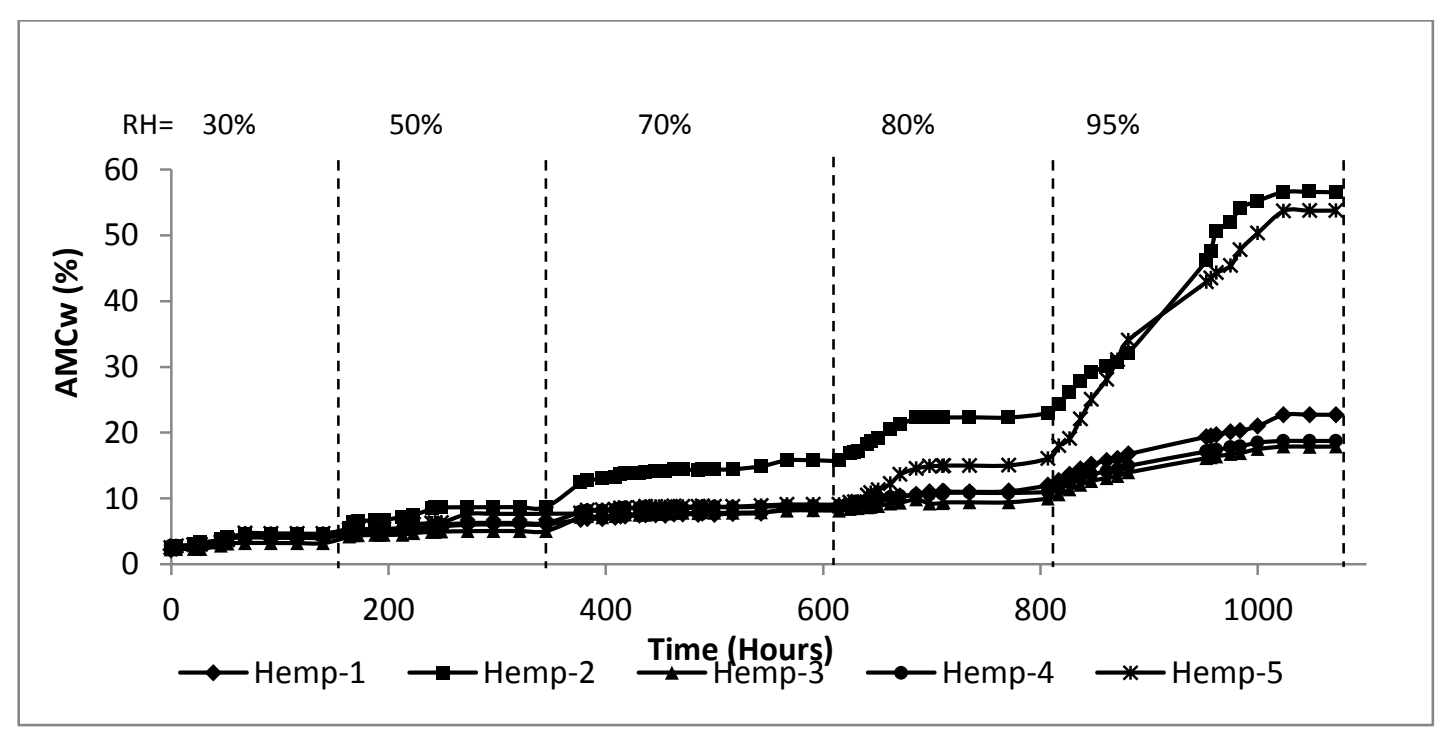

Fig. 13. Adsorption kinetics of the hemp insulations.

\subsection{Vapour diffusion resistance factor ( $\mu$ value)}

The test for determining vapour diffusion resistance factor were carried out for 10 days. The $\mu$ value and $S_{d}$ value of the insulation samples are shown in Table 4 and Fig. 14. 
Table 4. $\mu$ value and $S_{d}$ value of the insulation materials.

\begin{tabular}{lll|ll}
\hline & $\mu$ value (-) & & $S_{d}$ value $(\mathrm{m})$ & \\
\cline { 2 - 5 } & Dry Cup Test & Wet Cup Tets & Dry Cup Test & Wet Cup Tets \\
\hline Hemp-1 & 1.89 & 1.85 & 0.091 & 0.089 \\
Hemp-2 & 1.57 & 1.29 & 0.086 & 0.075 \\
Hemp-3 & 2.63 & 1.11 & 0.124 & 0.052 \\
Hemp-4 & 2.74 & 1.10 & 0.123 & 0.049 \\
Hemp-5 & - & 0.51 & - & 0.029 \\
\hline
\end{tabular}

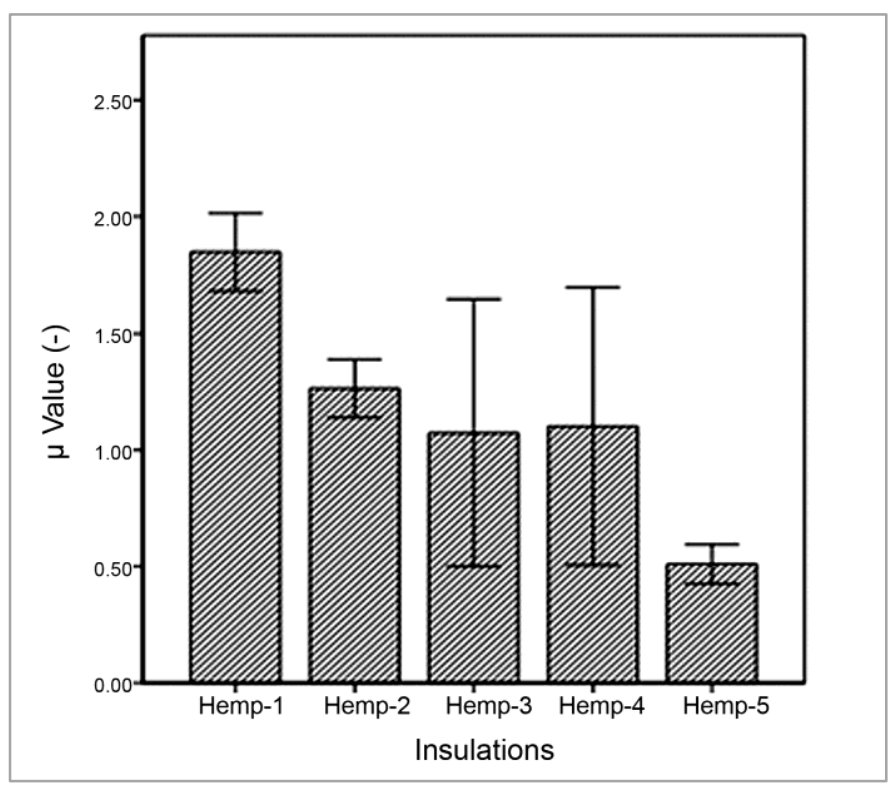

Fig. 14. Vapour diffusion resistance ( $\mu$ value) factor of the hemp insulation materials during the wet cup test with 1 standard deviation.

Hemp- 5 shows the lowest $\mu$ value during the wet cup test whilst Hemp- 1 shows the highest $\mu$ value. Only the wet cup test is performed for Hemp-5 due to the lack of required number of samples. The vapour diffusion resistance factor of Hemp-5 requires further investigation as this value was less than the value of the vapour diffusion resistance factor of air.

During the dry cup test, Hemp-4 exhibits the highest $\mu$ value whilst Hemp-2 exhibits the lowest $\mu$ value. There are considerable deviations from the mean $\mu$ value in Hemp-3 and Hemp-4 samples during the wet cup and dry cup tests, respectively. It can be observed in Table 4 that the $\mu$ value of insulation materials obtained by dry 
cup tests are always higher than the corresponding $\mu$ values obtained by the wet cup tests. This is expected since vapour permeability is moisture dependent and the value of vapour permeability rises with the increase of moisture content of insulation materials.

It is plausible that the observed variations in the $\mu$ value of the insulation samples are due to the possible variations in porosity and tortuosity of these materials.

The non-homogeneity of some of the hemp insulations, as reflected by the high standard deviation from the mean $\mu$ value, may make it difficult to predict the actual performance of the insulation materials in terms of their vapour transmission.

\subsection{Water absorption coefficient or A-value}

Fig. 15 shows the $\Delta m_{t}$ versus square root of time $(\sqrt{s}$, where s is seconds) plots for Hemp-1, Hemp-2, Hemp-3, Hemp-4 and Hemp-5 insulation materials, respectively. In all the cases, the graph of $\Delta m_{t}$ against $\sqrt{s}$ does not give a straight line, but curves. In these cases, the A value can be determined by applying either Eq. 19 or

Eq. 20. For the tests carried out, Eq. 19 was applied and the $A$ values were determined in terms of $A_{w, 24}$.

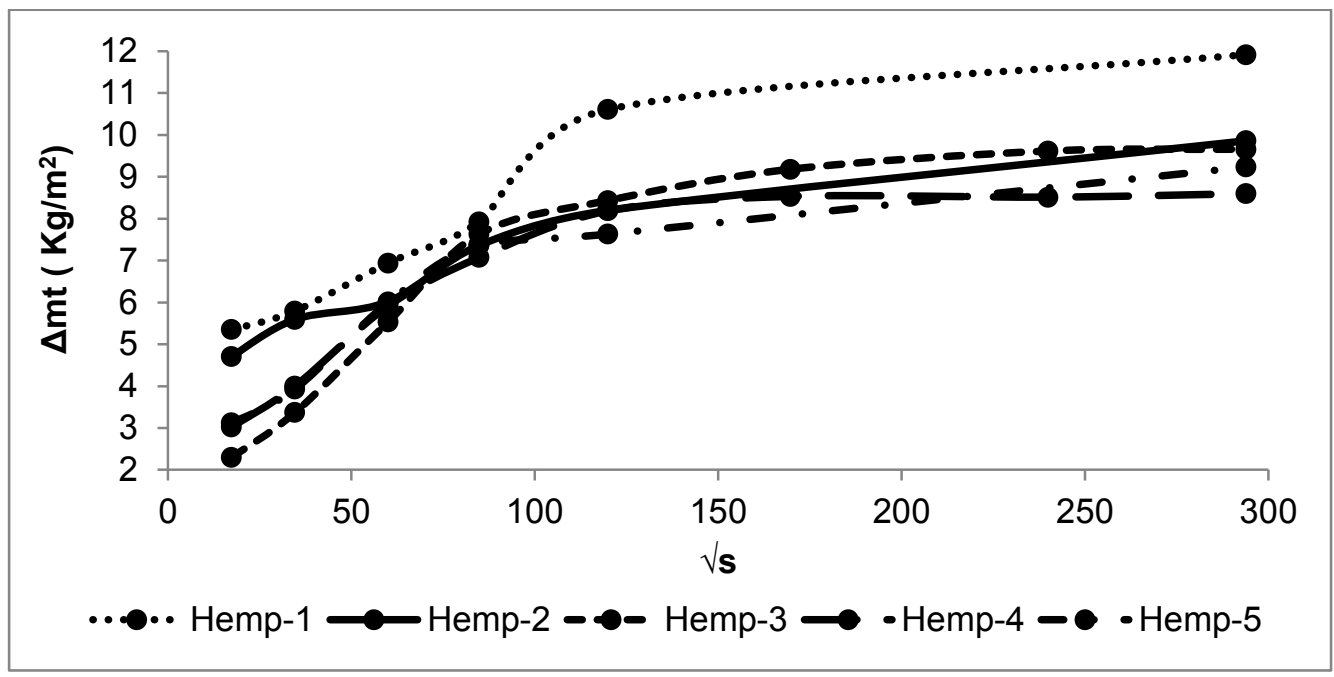

Fig. 15. $\Delta \mathrm{m}_{\mathrm{t}}$ versus $\sqrt{s}$ plot for Hemp-1, Hemp-2, Hemp-3, Hemp-4 and Hemp-5 insulations (average values of 3 samples). 
Fig. 16 and Table 5 show the $A_{w, 24}$ values of Hemp-1, Hemp-2, Hemp-3, Hemp-4 and Hemp-5. Except Hemp-1 insulation, all the hemp insulation materials exhibit similar $A_{w, 24}$ values.

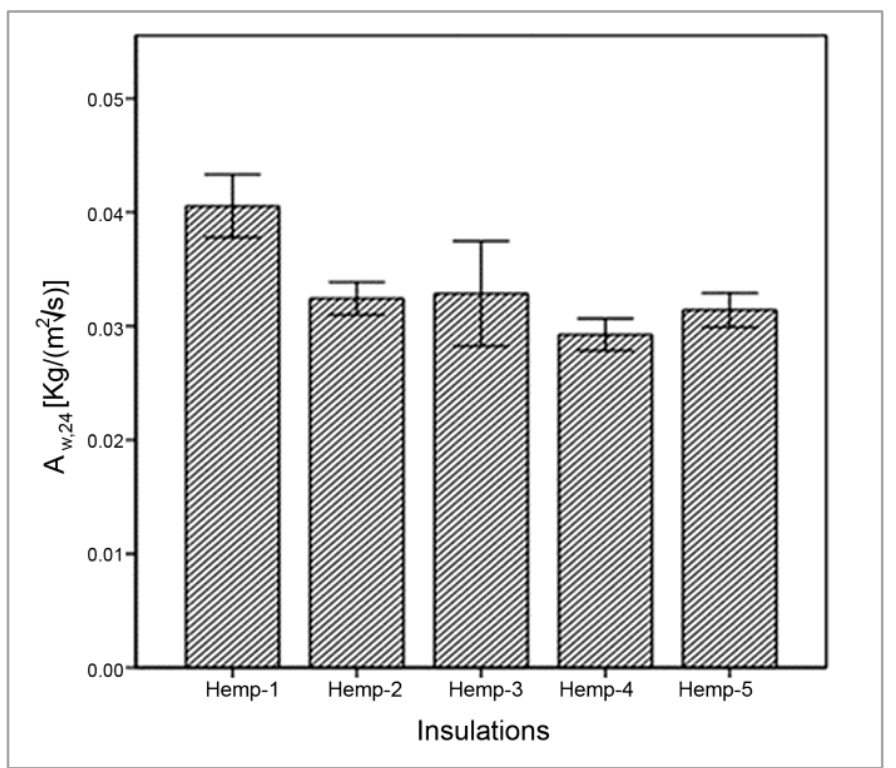

Fig. 16. The A value of hemp insulations with 1 standard deviation.

During the determination of the $A$ values, it is observed that the long-term contact with liquid water can change the structure of the insulation surface that is in contact with water. Fibres are hardened and compacted near the surface and the density near the surface seems to increase as a result. The implication of these changes on the thermal conductivity and vapour diffusion may need further studies.

Table 5. Mean $A_{w, 24}$ value of the hemp insulation materials.

\begin{tabular}{ll}
\hline Insulations & A value $\left(\mathrm{Kg} / \mathrm{m}^{2} \sqrt{s}\right)$ \\
\hline Hemp-1 & 0.041 \\
Hemp-2 & 0.034 \\
Hemp-3 & 0.033 \\
Hemp-4 & 0.029 \\
Hemp-5 & 0.031 \\
\hline
\end{tabular}

\subsection{Practical moisture buffer value (MBV $\left.V_{\text {practical }}\right)$}

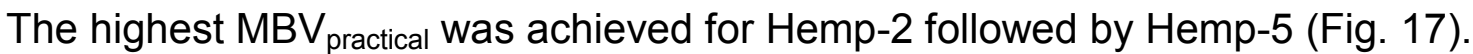

Hemp-4 showed the lowest value for $\mathrm{MBV}_{\text {practical. }}$ 


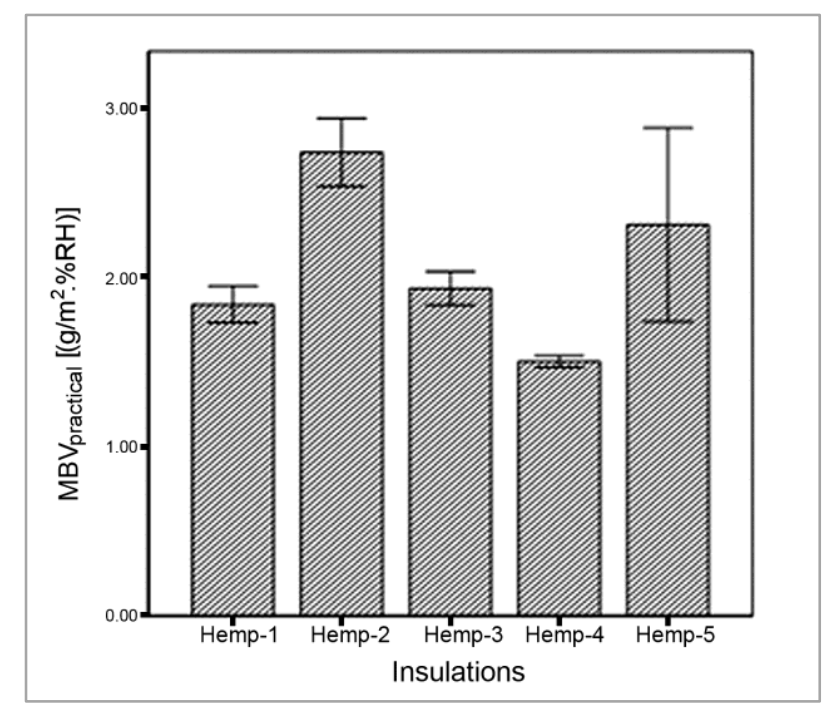

Fig. 17. Practical moisture buffer value of the insulations with 1 standard deviation.

The kinetics of moisture buffer the actual performance of the insulation materials is shown in Fig.18.

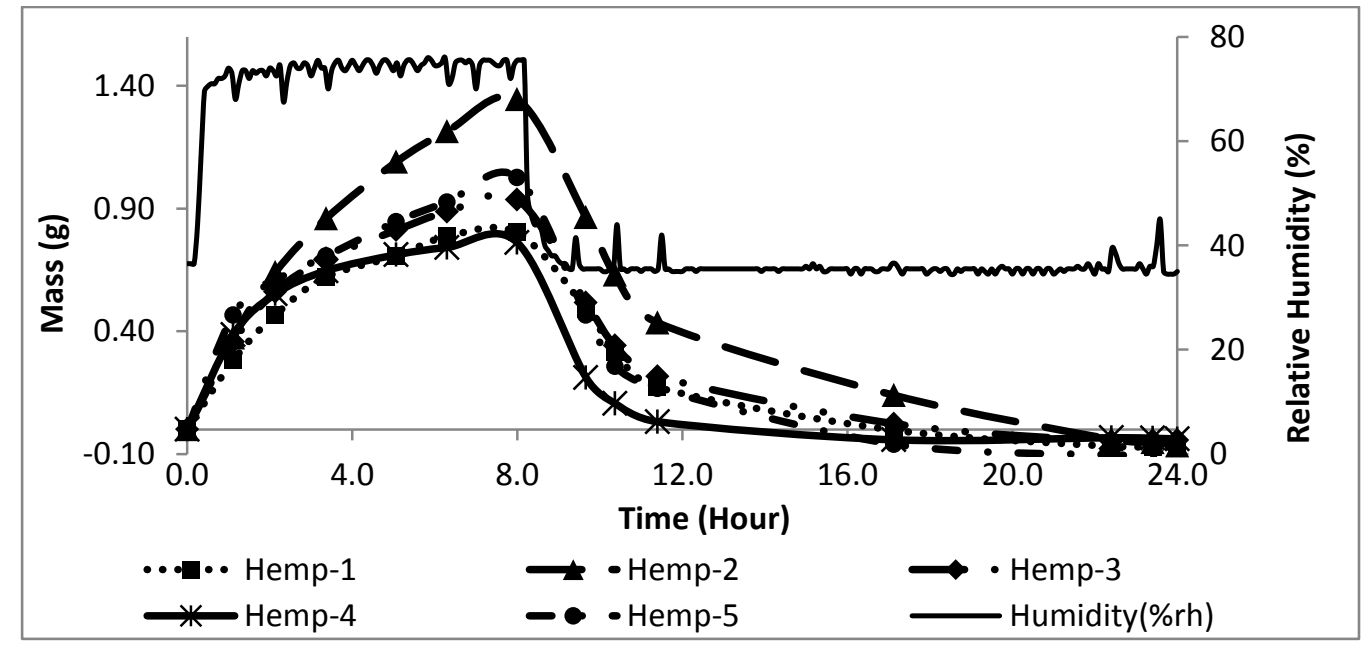

Fig. 18. Kinetics of moisture buffer of hemp insulations during the final cycle.

If the experimental results are explored in terms of adsorption isotherm, it can be observed that Hemp-2 and Hemp-5 show high moisture adsorption capacity and this is also reflected in their corresponding MBV practical values. Hemp-1, Hemp-3 and Hemp-4 are in the mid-range in hygroscopic capacity, which is also their behaviour in terms of their corresponding $\mathrm{MBV}_{\text {practical }}$ values. In terms of practical moisture buffer value classes (Table 6), Hemp-2 and Hemp-5 can be classified as 'Excellent' and Hemp-1, Hemp-3 and Hemp-4 can be classified as 'Good'. Hence, all the hemp 
insulation materials belong to the two upper most classes in terms of moisture buffering efficiency.

Table 6. Ranges for practical Moisture Buffer Value classes [8]

MBVpractical class Minimum MBV level Maximum MBV level $\left[\mathrm{g} /\left(\mathrm{m}^{2} . \% \mathrm{RH}\right)\right] \quad\left[\mathrm{g} /\left(\mathrm{m}^{2} . \% \mathrm{RH}\right)\right]$

\begin{tabular}{lll}
\hline Negligible & 0 & 0.2 \\
Limited & 0.2 & 0.5 \\
Moderate & 0.5 & 1.0 \\
Good & 1.0 & 2.0 \\
Excellent & 2.0 & - \\
\hline
\end{tabular}

Moisture buffer value reduces when $12.5 \mathrm{~mm}$ paper backed gypsum plasterboards of same length and width of the corresponding samples are installed on the upper surfaces of the hemp insulation materials. The comparative moisture buffer values are shown in Figure 19 where '(PB)' denotes the corresponding insulation samples with plasterboard (hemp-plasterboard system). It can be noted that the application of plasterboard reduces the mean moisture buffer values of Hemp-1, Hemp-2, Hemp-3, Hemp-4 and Hemp-5 insulations by $6.6 \%, 31.5 \%, 4.5 \%, 7.0 \%$ and $17.8 \%$, respectively. The difference in the percentage of reduction of the moisture buffer value of the samples may be due to the porosity of the corresponding insulation samples.

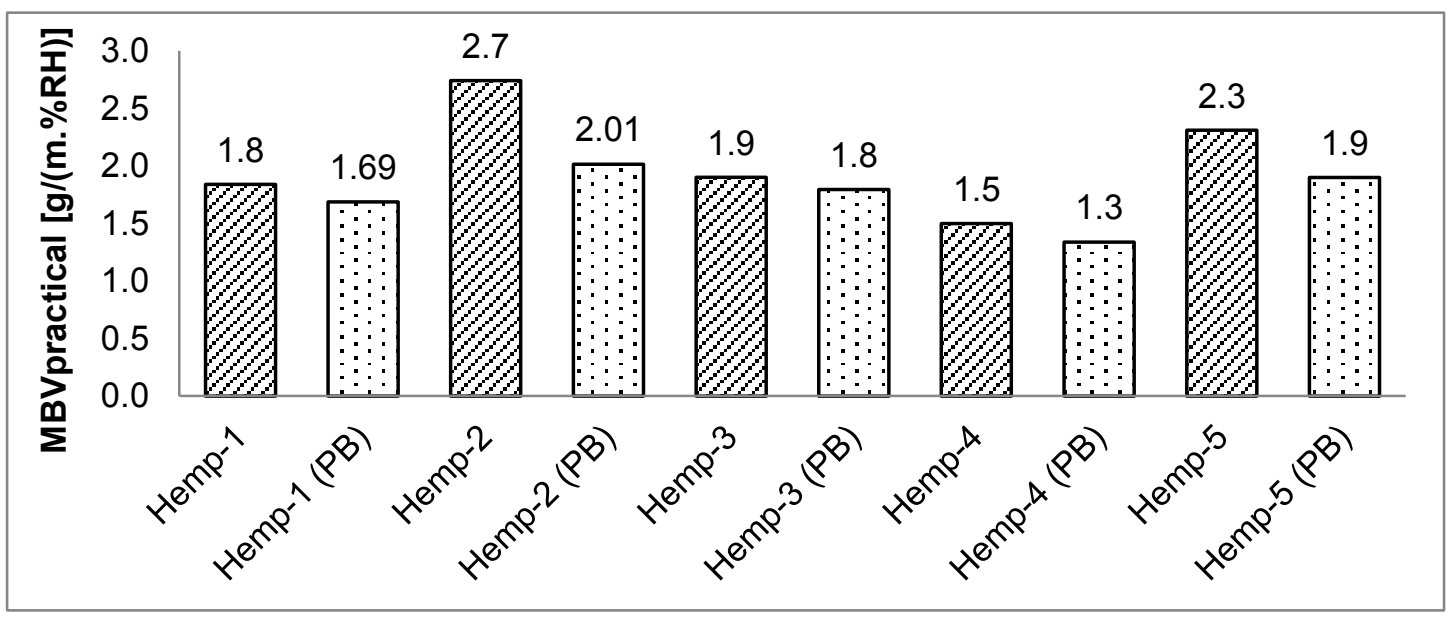

Fig. 19. Moisture buffer values of hemp insulation and hemp-plasterboard system. 
It can also be noticed that, despite the reduction of moisture buffer values, the moisture buffer classes of the insulation-plasterboard system are same as the moisture buffer classes of the corresponding insulation materials.

\section{Conclusions}

Five hemp insulation materials available in the UK market are characterised in terms of their key hygric properties, namely adsorption-desorption isotherm, moisture buffer value, vapour diffusion resistance factor and water absorption coefficient. In relation to adsorption-desorption isotherm, hemp insulations exhibited varying moisture adsorption pattern and capacity. The insulation materials with more active area for monolayer water sorption also showed higher water adsorption capacity during high water activity. Hysteresis is more pronounced in insulations containing hemp shiv or wood fibre. The relatively dense hemp insulations showed less standard deviation in adsorption capacity, whereas hemp insulations of relatively lower density showed higher standard deviation in adsorption capacity. In relation to practical moisture buffer value, Hemp-2 and Hemp-5 exhibited 'Excellent' performance while Hemp-1, Hemp-3 and Hemp-4 showed 'Good' performance. The hemp insulations with higher moisture adsorption capacity showed higher $M B V_{\text {practical }}$ values. In terms of $\mu$ values, considerable variations among the insulation materials were observed. Hemp-5 showed the lowest $\mu$ value whilst Hemp-1 showed the highest $\mu$ value during the wet cup test. During the dry cup test, Hemp-4 exhibited the highest $\mu$ value whilst Hemp-2 exhibited the lowest $\mu$ value. There were considerable deviations from the mean $\mu$ value in Hemp-3 and Hemp-4 during the wet cup and dry cup tests, respectively. The $\mu$ value of insulation materials obtained by dry cup tests were always higher than those obtained by the wet cup tests. It is plausible that fibre processing, fibrous structure, tortuosity and porosity of the 
insulations influence their moisture sorption and moisture diffusion properties. $A_{w, 24}$ values of Hemp-2, Hemp-3, Hemp-4 and Hemp-5 insulation materials were equal up to the second decimal point. The $A_{w, 24}$ value of Hemp-1 was $33 \%$ higher than the $A_{w, 24}$ values of other hemp insulations. During the $A$ value tests, it was observed that long-term contact with liquid water hardened the surface of the hemp insulations and increased the density of that surface. This change in the surface structure may influence the thermal conductivity and vapour diffusion resistance factor of hemp insulations. Performance of hemp insulation at high temperature was not explored as the focus of the present study was the building application of hemp thermal insulations.

Considerable differences in the hygric properties of the investigated hemp insulation materials were observed. Once their key hygric parameters are determined, numerical hygrothermal simulations can be performed to explore the suitability of these insulation materials for different wall types and weather conditions. Based on the initial performance, the insulation materials can be optimised for better performance.

Acknowledgements: This research was financially supported by the Technology Strategy Board (DTI Project No: TP A0089J), UK, to whom the authors extend their most grateful acknowledgement.

\section{References}

[1] Zach J, Korjenicb A, Petranek V, Hroudova J, Bednar T. Performance evaluation and research of alternative thermal insulations based on sheep wool. Energy and Buildings. 2012;49:246-53.

[2] Viitanen H, Vinha J, Salminen K, Ojanen T, Peuhkuri R, Paajanen L, et al. Moisture and Biodeterioration Risk of Building Materials and Structures. 2010;33(3):201-24.

[3] Nic M, Jirat J, Kosata B. Compendium of Chemical Terminology: Gold Book. International Union of Pure and Applied Chemistry; 2012.

[4] Snoeyink V, I, Summers R, S. Adsorption of organic compounds. In: Association AWW, editor. Water Quality and Treatment: A Handbook of Community Water Supplies. 5th ed. US: McGraw-Hill Inc; 1999.

[5] Osborne M. Adsorption Isotherms. 2004. 
[6] Hill CAS, Norton A, Newman G. Water vapor sorption behavior of natural fibers. Journal of Applied Polymer Science. 2009;112(3):1524-37.

[7] Collet F, Achchaq F, Djellab K, Marmoret BH. Water vapor properties of two hemp wools manufactured with different treatments. Construction and Building Materials. 2011;25:1079-85.

[8] Condon J, B. Surface Area and Porosity Determinations by Physisorption: Measurements and Theory.

[9] Rode C. Moisture buffering of building materials. Technical University of Denmark; 2005.

[10] Association JS. JIS A 1470-1. Test method of adsorption/desorption efficiency for building materials to regulate an indoor humidity - part 1: response method of humidity

Japan: Japanese Standards Association 2002.

[11] ISO 24353. Hygrothermal performance of building materials and products -- Determination of moisture adsorption/desorption properties in response to humidity variation. Switzerland:

International Organization for Standardization; 2008.

[12] Padfield T, Jensen L. Humidity buffering by absorbent materials. 2010.

[13] Hens HSLC. Building physics - heat, air and moisture : fundamentals and engineering methods with examples and exercises. Berlin: Ernst \& Sohn; 2007.

[14] Institute BS. BS EN ISO 12571. Hygrothermal performance of building materials and products. Determination of hygroscopic sorption propertie. London: BSI; 2013.

[15] Timmermann EO. Multilayer sorption parameters: BET or GAB values? Colloids and Surfaces A: Physicochem Eng Aspects. 2003;220:235-60.

[16] Institute BS. BS EN 12086. Thermal insulating products for building applications -Determination of water vapour transmission properties. London: BSI; 1997.

[17] Institute BS. BS EN ISO 15148: Hygrothermal performance of building materials and products Determination of water absorption coefficient by partial immersion. London: BSI; 2002.

[18] Nilsson D, Svennerstedt B, Wretfors C. Adsorption Equilibrium Moisture Contents of Flax Straw, Hemp Stalks and Reed Canary Grass. Biosystems Engineering. 2005;91(1):35-43.

[19] Blahovec J, Yanniotis S. Modified Classification of Sorption Isotherms. Journal of Food Engineering. 2009;9:72-7. 